\title{
Determination of Carbamazepine by Chemiluminescence Detection Using Chemically Prepared Tris(2,2'-bipyridine)- ruthenium(III) as Oxidant
}

\author{
Sang Hak LEE, ${ }^{* \dagger}$ Ming LI,* and Jung Kee SuH** \\ *Department of Chemistry, Kyungpook National University, Taegu 702-701, Korea \\ **Korea Research Institute of Standards and Science, Taejon 305-600, Korea
}

\begin{abstract}
A new chemiluminescence method for the determination of carbamazepine (CBZ) has been developed. The method is based on the chemiluminescence produced in the reaction of tris(2,2'-bipyridine)ruthenium(III) and CBZ in an acidic medium. The chemiluminescence intensity was enhanced by organic solvents in the reaction system. Under the optimum experimental conditions, the calibration curve was linear over the range $4.0 \times 10^{-3}-8.6 \times 10^{-7} \mathrm{~mol} / \mathrm{L}$ for CBZ. The detection limit $(S / N=3)$ was $2.5 \times 10^{-7} \mathrm{~mol} / \mathrm{L}$ and the relative standard deviation of six replicate measurements was $2.6 \%$ for $4.0 \times 10^{-4} \mathrm{~mol} / \mathrm{L}$ of CBZ. The possible reaction mechanism were also discussed. The chemiluminescence method was successfully applied to assay the CBZ contents in pharmaceutical tablets.
\end{abstract}

(Received November 5, 2002; Accepted February 19, 2003)

\section{Introduction}

Carbamazepine (5H-dibenzo[b,f]azepine-5-carboxamide, CBZ) is one of the most frequently used drugs for treatment of epileptic seizures, trigeminal neuralgia and psychiatric disorders. ${ }^{1,2}$ It has a highly lipophilic, neutral tricyclic structure. CBZ is usually administered at daily oral doses ranging from 200 to $1200 \mathrm{mg}$, which give rise to drug plasma levels of $4-12$ $\mu \mathrm{g} / \mathrm{ml}^{3}$

Gas chromatography has often been used for the determination of CBZ.,5 However, this method usually needs complicated derivatization procedures. High performance liquid chromatography is most widely used for the determination of CBZ with $\mathrm{UV}^{6-10}$ or mass detection. ${ }^{11}$ Some papers have recently been published for the determination of CBZ by means of micellar electrokinetic chromatography. ${ }^{12,13}$ Fluorescence polarization immunoassay method was also used for the routine therapeutic drug monitoring of CBZ alone in plasma. But because of using antibodies in these procedures, this method sometimes leads to overestimation of CBZ in plasma. ${ }^{14}$ Chemiluminescence offers an attractive means of detection of trace analysis due to its low detection limit and wide dynamic range, with relatively simple instrumentation. Tris(2,2'-bipyridyl)ruthenium(III) is one of the most frequently used chemiluminogenic oxidants. Lots of papers have reported the determination of different types of drugs such as hydrazine, codeine and heroin by chemiluminescence methods using electrogenerated ruthenium(III) derivatives as oxidant. ${ }^{15-17}$ The electrogenerated ruthenium(III) chemiluminescence method can offer a reliable and constant source of ruthenium(III). However, it has certain limitations including electrode fouling and the need for frequent re-conditioning of the electrode surface to maintain chemiluminescence response. ${ }^{18}$ The chemically prepared ruthenium(III) chemiluminescence method has

† To whom correspondence should be addressed.

E-mail: shlee@knu.ac.kr advantages of speed and simplicity while it has the disadvantages of the inherent instability of reagent with respect to reduction. ${ }^{19}$ Recently, some papers have appeared on analytically successful applications by utilizing the chemiluminescence intensity from the chemically prepared $\mathrm{Ru}(\text { bipy })_{3}^{3+} \cdot{ }^{20-22}$

This paper describes the development of chemiluminometric method for the determination of CBZ, based on the chemically prepared tris (2,2'-bipyridine)ruthenium(III) by reaction of $\mathrm{PbO}_{2}$ and $\mathrm{Ru}$ (bipy) ${ }_{3}^{2+}$ in acidic medium. The effects of $\mathrm{pH}$ and concentrations of $\mathrm{Ru}(\text { bipy })_{3}{ }^{3+}$ and organic solvent on the chemiluminescent intensity have been investigated. The present method has been successfully applied to the determination of CBZ in tablets.

\section{Experimental}

\section{Instrumentation}

A simple two line flow injection analysis manifold was employed. An Ismatec Model 404 peristaltic pump with Tygon tube $(1.2 \mathrm{~mm}$ i.d.) was used to deliver both streams at a maximum total flow rate of $4 \mathrm{~mL} / \mathrm{min}$ for all experiments. The flow injection analysis manifold tubing was Bran + Luebbe (Roselle IL, USA) Tygon R3603 (0.51 mm i.d.); manual injection of either analyte or reagent solutions was accomplished using a Rheodyne (Cotati, California, USA) Model 7125 six port valve. The two streams merged at a Tpiece, positioned $20 \mathrm{~mm}$ from a coiled glass flow cell $(1.0 \mathrm{~mm}$ i.d., $20 \mathrm{~mm}$ total diameter) All chemiluminescence measurements were performed using a Spex (Edison, NJ, USA) Model FL111 spectrofluorometer equipped with a Hamamatsu R238 photomultiplier. ${ }^{23}$ The instrumental parameters were controlled by Spex DM3000 software. For the chemiluminescence measurement, the light source of the spectrofluorometer was switched off. The slit width of the emission monochromator used was $5.0 \mathrm{~mm}$. The high voltage for the photomultiplier tube was set to $900 \mathrm{~V}$. A Mettler Toledo 


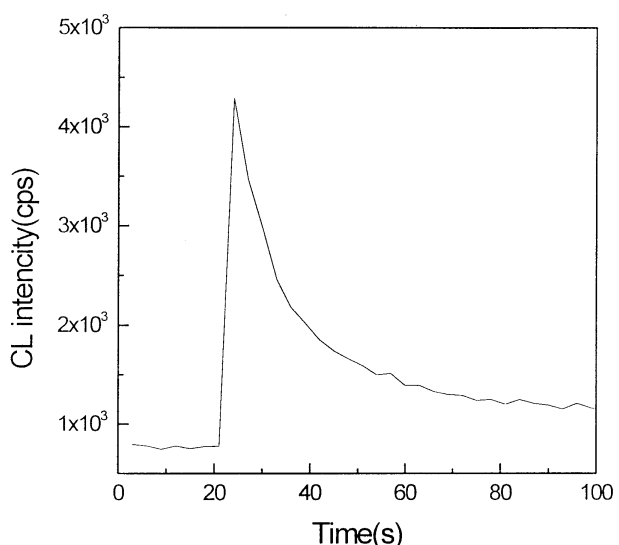

Fig. $1 \mathrm{CL}$ intensity $v s$. time profile: [CBZ], $5.0 \times 10^{-5} \mathrm{M}$; $\left[\mathrm{Ru}(\text { bipy })_{3}^{3+}\right.$ ], 2 mM; pH 4.0.

(CH-8603 Schwerzenbach, Switzerland) MA235 pH/Ion analyzer was used for $\mathrm{pH}$ measurememts.

\section{Reagents}

Carbamazepine (5H-dibenzo[ $b, f]$ azepine-5-carboxamide, CBZ), 10,11-dihydrocarbamazepine (10,11-dihydro-5 $H$ dibenzo $[b, f]$ azepine-5-carboxamide $)$ and tris(2,2'-bipyridine)ruthenium chloride were obtained from Sigma (St. Louis, MO, USA). Each stock solution of the CBZ $\left(8.0 \times 10^{-3} \mathrm{~mol} / \mathrm{L}\right)$ was prepared by dissolving the appropriate amount of reagent in ethanol solution and was stable for at least 3 months when stored at $4^{\circ} \mathrm{C}$. Each stock solution of tris(2,2'-bipyridine)ruthenium chloride was prepared by dissolving the appropriate amount of reagent in $0.5 \mathrm{M}$ sulfuric acid solution and was stored at $4{ }^{\circ} \mathrm{C}$. Ru(bipy) $3^{3+}$ solution was prepared off-line, $0.1 \mathrm{~g}$ lead dioxide was added to acidic $5 \mathrm{~mL} 2.0 \mathrm{mM} \mathrm{Ru}$ (bipy) $)_{3}{ }^{2+} .{ }^{24}$ After $5 \mathrm{~min}$, the resultant suspension was allowed to settle prior to filtering through a membrane filter assembly $(0.2 \mu \mathrm{m})$ followed by vigorous mixing. Produced $\mathrm{Ru}(\text { bipy })_{3}{ }^{3+}$ solutions were stable for $2 \mathrm{~h}$ in the $0.05 \mathrm{M}$ sulfuric acid solution. The concentration of $\mathrm{Ru}$ (bipy) $3_{3}{ }^{3+}$ was determined by spectrophotometric measurement at $\lambda_{\max }=675 \mathrm{~nm}\left(\varepsilon=420 \mathrm{~cm}^{-1} \mathrm{M}^{-1}\right){ }^{25}$ Methanl, ethanol, 2-propanol and sec-butanol, were from Oriental Chemical Industries (Inchon, Korea). Potassium chloride, hydrochloric acid and potassium dihydrogenphosphate were purchased from Aldrich (Milwaukee, USA). All solutions were prepared by weighing suitable amounts of the reagent grade material and diluting with water. All experiments were performed with analytical-reagent grade chemicals and Milli-Q purified water.

\section{Sample preparation}

Ten tablets were weighed and crushed. An appropriate weight of the powdered CBZ drug (equivalent to $20.0 \mathrm{mg}$ ) was transfered into a $100 \mathrm{~mL}$ volumetric flask and diluted to the mark with ethanol. After sonication for $15 \mathrm{~min}$, the remaining insoluble residue was filtrated off. The filtrate was directly injected to the flow system.

\section{Procedure}

A sulfuric acid $(0.05 \mathrm{M})$ carrier stream was employed into which $\mathrm{Ru}(\text { bipy })_{3^{3+}}$ was injected $(100 \mu \mathrm{L})$, whilst a second stream delivered analyte standard and sample solutions $(40 \mu \mathrm{L})$. The measuring chamber was kept at a constant temperature of $25^{\circ} \mathrm{C}$. After each measurement, the reaction cell was rinsed

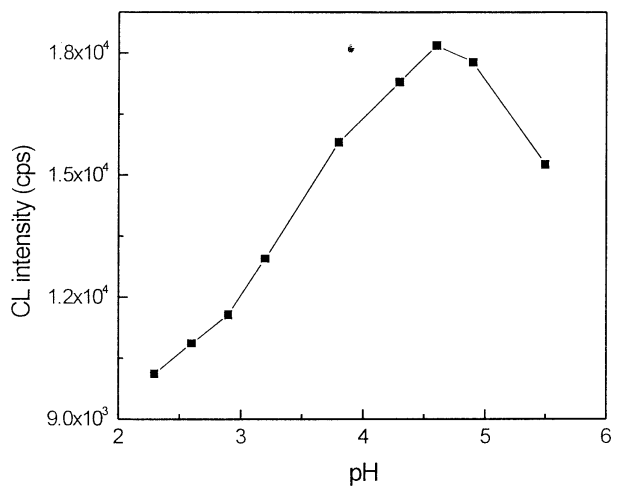

Fig. 2 Effect of $\mathrm{pH}$ on $\mathrm{CL}$ intensity: [CBZ], $4.0 \times 10^{-5} \mathrm{M}$; $\left[\mathrm{Ru}(\text { bipy })_{3}{ }^{3+}\right], 2 \mathrm{mM}$.

with water (total volume of $10 \mathrm{~mL}$ ), followed by a second measurement.

\section{Results and Discussion}

\section{CL characteristics of $C B Z$}

Little CL was observed in acidic $\mathrm{Ce}^{4+}$ and basic $\mathrm{H}_{2} \mathrm{O}_{2}$ solution. Weak CL was observed when acidic $\mathrm{KMnO}_{4}$ was mixed with CBZ. A useful large intensity CL was observed in the acidic $\mathrm{Ru}$ (bipy) $3^{3+}$ solution, which would be enhanced greatly by the organic solvent. The CL spectrum of $5.0 \times 10^{-5} \mathrm{M} \mathrm{CBZ}$ with 2 $\mathrm{mM} \mathrm{Ru}(\text { bipy })_{3}{ }^{3+}$ solution at $\mathrm{pH} 4.0$ is shown in Fig. 1. It takes 3 $\mathrm{s}$ to reach the maximum $\mathrm{CL}$ intensity from the start of the reaction of the two reagents.

\section{Effect of $p H$}

The effects of $\mathrm{pH}$ on the $\mathrm{CL}$ intensity for the CBZ$\mathrm{Ru}$ (bipy) $3^{3+}$ aqueous solution are shown in Fig. 2. The $\mathrm{pH}$ were adjusted by $0.2 \mathrm{M} \mathrm{KCl}-0.2 \mathrm{M} \mathrm{HCl}$ and $0.2 \mathrm{M} \mathrm{KH}_{2} \mathrm{PO}_{4}-0.2 \mathrm{M}$ $\mathrm{HCl}$ buffer solution. At concentrations of $4.0 \times 10^{-5} \mathrm{M} \mathrm{CBZ}$ and $2 \mathrm{mM} \mathrm{Ru}$ (bipy) $3^{3+} \mathrm{CL}$ intensity was examined over the $\mathrm{pH}$ range from 1.0 to 6.0 . $\mathrm{pH}$ above 6.0 was not tested, because $\mathrm{Ru}$ (bipy) $3^{3+}$ reacted with hydroxide ion and emitted light. Figure 2 shows that the maximum CL occurred at $\mathrm{pH} 4.5$. Consequently, the $\mathrm{pH}$ of each solution was maintained at 4.5 in the subsequent study.

\section{Effect of concentration of Ru(bipy) $3^{3+}$}

The effect of concentration of $\mathrm{Ru}($ bipy $) 3^{3+}$ on the CL intensity was studied at $\mathrm{pH} 4.5$ and $4.0 \times 10^{-5} \mathrm{~mol} / \mathrm{L} \mathrm{CBZ}$ using different concentrations of $\mathrm{Ru}(\text { bipy })_{3}{ }^{3+}$ from $0.1 \mathrm{mM}$ to $10.0 \mathrm{mM}$. The results are shown in Fig. 3. The maximum was reached when the concentration of $\mathrm{Ru}$ (bipy) $3^{3+}$ was $2 \mathrm{mM}$. Therefore, a concentration of $2 \mathrm{mM}$ of Ru(bipy) $3^{3+}$ was recommended.

\section{Effect of organic solvent concentration}

The effect of organic solvent on the CL intensity was studied at $\mathrm{pH} 4.5,4.0 \times 10^{-5} \mathrm{~mol} / \mathrm{L} \mathrm{CBZ}$ and $2 \mathrm{mM} \mathrm{Ru}(\text { bipy })_{3}{ }^{3+}$ using $20 \%$ quantitative of organic solvents. The organic solvents tested in this study were methanol, ethanol, 2-propanol, secbutanol. The results (Fig. 4) show enhanced CL intensities without significant increases in the background signals. This may be attributed to the increased CL quantum efficiency to some extent. In a CL reaction, the intensity depends on the rate of the reaction as well as on the quantum efficiency of the system. ${ }^{26}$ The quantum efficiency of luminescence in most 


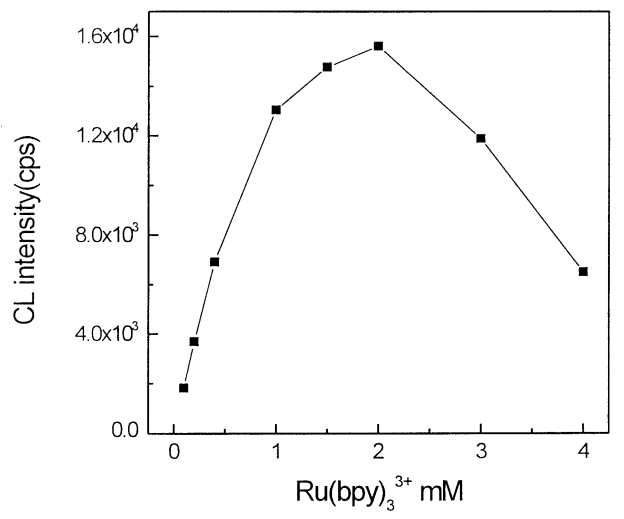

Fig. 3 Effect of $\mathrm{Ru}(\text { bipy })_{3}{ }^{3+}$ concentration on $\mathrm{CL}$ intensity: [CBZ], $4.0 \times 10^{-5} \mathrm{M} ; \mathrm{pH} 4.5$.

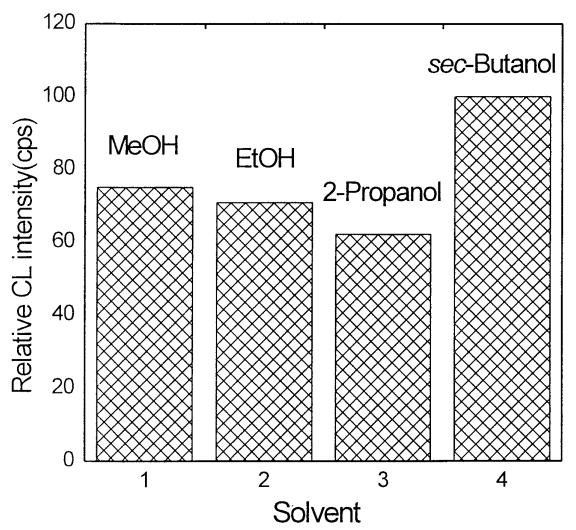

Fig. 4 Effect of organic solvent on CL intensity: [CBZ], $4.0 \times 10^{-5}$ $\mathrm{M} ;\left[\mathrm{Ru}(\text { bipy })_{3}{ }^{3+}\right], 2 \mathrm{mM}$; $\mathrm{pH} 4.5$.

luminescent molecules increases with increasing solvent viscosity because the increased solvent viscosity improves the probability for deactivation by external conversion. The highest CL intensities were obtained in sec-butanol, which has the highest viscosity among the alcohols used in this paper. Figure 5 shows that the CL intensities depend on the content of secbutanol. The optimum concentration of sec-butanol was $30 \%$ (v:v).

\section{Effect of flow rate}

The flow rate of the carrier solutions was studied over the range $0.5-4.0 \mathrm{~mL} / \mathrm{min}$, while keeping all other conditions constant. The obtained result shows that $2.5 \mathrm{~mL} / \mathrm{min}$ was the best flow rate for CBZ determination.

\section{Calibration curve for the determination of $C B Z$}

We wanted to prepare a calibration curve to determine CBZ; thus eleven CBZ standard solutions were injected to the carrier stream containing 30\% sec-butanol, and CL intensity values which were linearly proportional to $\mathrm{CBZ}$ concentration were found. Figure 6 shows the calibration curve of CBZ. The experimental conditions of $\mathrm{pH}$, the concentration of $\mathrm{Ru}(\text { bipy })_{3}{ }^{3+}$ and sec-butanol were $4.5,2 \mathrm{mM}$ and $30 \%$, respectively. The linear dynamic range and the detection limit were $4.0 \times 10^{-3}$ $8.6 \times 10^{-7} \mathrm{~mol} / \mathrm{L}, 2.5 \times 10^{-7} \mathrm{~mol} / \mathrm{L}$, respectively. The correlation coefficient for this plot was 0.9996 , and the relative standard deviation of six replicate measurements is $2.6 \%$ for 4.0 $\times 10^{-4} \mathrm{M} \mathrm{CBZ}$.

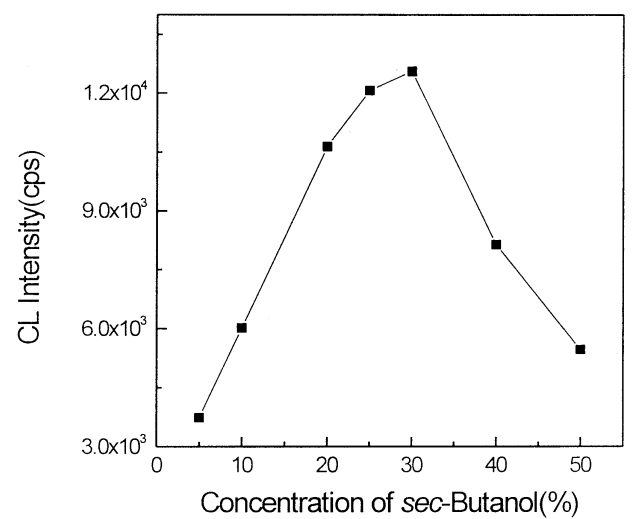

Fig. 5 Effect of sec-butanol concentration on CL intensity: [CBZ], $4.0 \times 10^{-5} \mathrm{M} ;\left[\mathrm{Ru}(\text { bipy })_{3}^{3+}\right], 2 \mathrm{mM} ; \mathrm{pH} 4.5$.

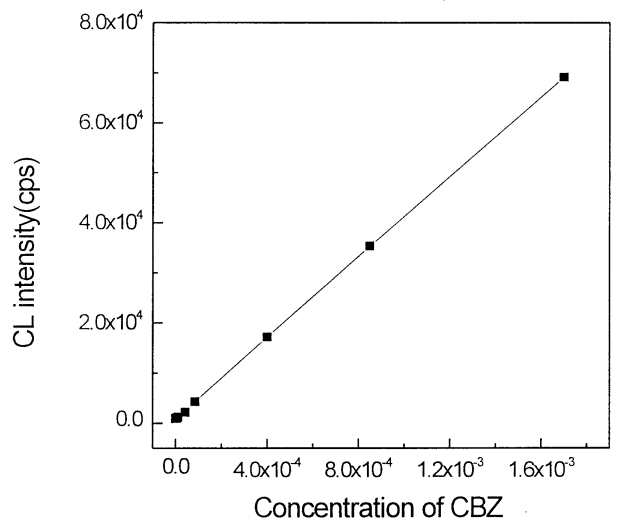

Fig. 6 Calibration curve of $\mathrm{CBZ}:\left[\mathrm{Ru}(\mathrm{bipy}) \mathrm{3}^{3+}\right], 2 \mathrm{mM}$; $[\mathrm{sec}-$ butanol], 30\%; pH 4.5 .

\section{Comparison with other methods}

The common method for determination of CBZ was LC-UV method. The main limitation of this method is a relatively low linear dynamic range. Table 1 shows comparison of the dynamic linear range and detection limit for CBZ afforded by the proposed CL method and by other methods.

\section{Interference studies}

Dihydrocarbamazepine is an intermediate compound that is formed in the synthesis of $\mathrm{CBZ}$ and frequently coexists in the CBZ tablets. Test results showed that dihydrocarbamazepine had not generated CL at $610 \mathrm{~nm}$ on reaction of $\mathrm{Ru}(\text { bipy })_{3}{ }^{3+}$. The effects of other common ions and compounds on CL were also studied. The tolerance of each foreign substances was taken as the largest amount yielding an error of less than $95 \%$ in the CL intensity of $1.0 \times 10^{-4} \mathrm{M}$ CBZ. The following foreign substances were considered to be tolerable: a 1000 -fold $\mathrm{Cl}^{-}$, $\mathrm{NO}_{3}{ }^{-}, \mathrm{SO}_{4}{ }^{2-}$, soluble starch, cellulose; 500-fold $\mathrm{Na}^{+}, \mathrm{Mg}^{2+} ; 10-$ fold glucose, methanol, ethanol, ascorbic acid.

\section{Application}

The proposed $\mathrm{Ru}$ (bipy) $3^{3+} \mathrm{CL}$ method was applied to assay two commercially available tablets of CBZ; the UV spectrophotometry method was also used. ${ }^{7}$ The analytical results obtained by both methods are listed in Table 2; they are in good agreement with each other.

The accuracy of the proposed method was verified by carrying out recovery studies. When commercial formulations spiked 
Table 1 Comparison of dynamic range for CBZ afforded by proposed method and other reported methods

\begin{tabular}{ccc}
\hline Method & Dynamic linear range/mol L & Reference \\
\hline GC & $9.5 \times 10^{-5}-4.6 \times 10^{-6}$ & 5 \\
UV & $6.8 \times 10^{-5}-8.5 \times 10^{-7}$ & 7 \\
UV & $6.3 \times 10^{-5}-4.2 \times 10^{-6}$ & 8 \\
UV & $6.0 \times 10^{-5}-2.1 \times 10^{-6}$ & 9 \\
CL & $4.0 \times 10^{-3}-8.5 \times 10^{-7}$ & Proposed \\
\hline
\end{tabular}

Table 2 Determination of CBZ in pharmaceutical preparations

\begin{tabular}{lccc}
\hline \multirow{2}{*}{ Formulation } & Labeled $^{\mathrm{a}}$ & \multicolumn{2}{c}{ Found $^{\mathrm{a}}($ mean \pm S.D., $n=5)$} \\
\cline { 3 - 4 } & & Proposed method & UV method \\
\hline Convatol $^{\circledR}$ & 200 & $197 \pm 3$ & $198 \pm 2$ \\
Tregretol $^{\circledR}$ & 200 & $196 \pm 2$ & $196 \pm 2$ \\
\hline
\end{tabular}

a. Expressed in mg per tablet.

with known amounts of standard solutions of CBZ were analyzed, quantitative recoveries of $99.2 \pm 0.92 \%(n=5)$ for CBZ was observed.

\section{Possible CL reaction mechanism}

$\mathrm{Ru}$ (bipy) $3_{3}{ }^{3+} \mathrm{CL}$ has proven to be a sensitive detection system for compounds which contain a secondary or tertiary aliphatic amine. The studied CBZ contains carbamoil tertiary amine. But it was found that the reaction mechanism is not similar to that reported tertiary amine.

In order to investigate reaction products, we used UV-Vis spectrophotometry to monitor the whole reaction process. The UV-Vis spectra showed the same pattern of the reaction for $\mathrm{CBZ}$ with permanganate. It was thought that $\mathrm{Ru}(\text { bipy })_{3}{ }^{3+}$ reacts with both benzene ring-conjugated ethylene sites of CBZ. $\mathrm{N}-(2-$ formyl)- $N$-(2-formyloxy)-urea appears to be the dominant product. The reaction mechanism in Fig. 7 was proposed.

\section{Conclusions}

The proposed direct CL method for determination of CBZ is simple, sensitive and precise, offering satisfactory linear dynamic ranges. As a result, it allows determination of $\mathrm{CBZ}$ with 2 orders wider linear dynamic range than those reported for various other analytical techniques. The proposed method was successively applied to analysis of CBZ contents in pharmaceutical tablets. This detection method could be easily connected LC or CE set-up to further investigate the CBZ metabolite in blood or urine samples.

\section{Acknowledgements}

The present work was supported by Korea Research Foundation Grant (KRF-2002-C00012).

\section{References}

1. M. A. Rogawski and R. J. Porter, Pharmacol. Rev., 1990, $42,224$.

2. F. Albani, R. Riva, and A. Baruzzi, Pharmacopsychiatry,

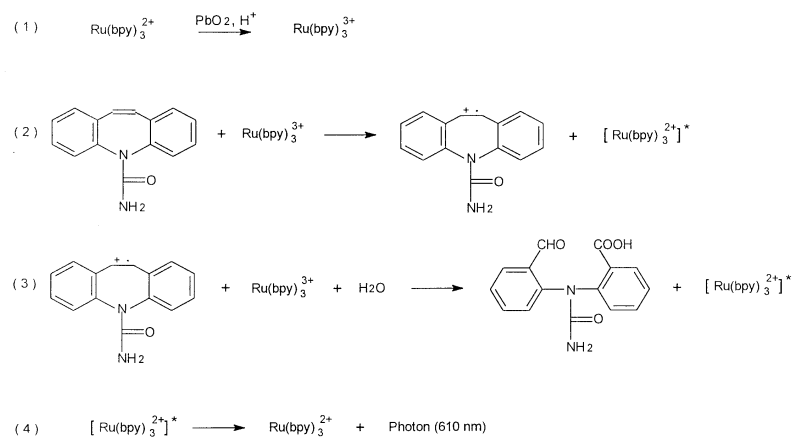

Fig. 7 Proposal for the reaction pathway between the CBZ and $\mathrm{Ru}(\text { bipy })_{3}{ }^{3+}$ in acidic aqueous solution.

1995, 28, 235.

3. R. H. Mattson, Epilepsia, 1995, 36, 22.

4. J. T. Burke and J. P. Thenot, J. Chromatogr. B, 1985, 340, 199.

5. M. L. Mashford, P. L. Ryan, and W. A. Thomson, J. Chromatogr. A, 1974, 89, 11.

6. M. M. Bhatti, G. D. Hanson, and L. Schultz, J. Pharm. Biomed. Anal., 1998, 16, 1233.

7. A. Volosov, M. Bialer, S. Xiaodong, E. Perucca, A. Sintor, and B. Yagen, J. Chromatogr. B, 2000, 738, 419.

8. R. Mandrioli, F. Albani, G. Casamenti, C. Sabbioni, and M. A. Raggi, J. Chromatogr. B, 2001, 762, 109.

9. A. Owen, J. N. Tettey, P. Morgan, M. Pirmohamed, and B. K. Park, J. Pham. Biomed. Anal., 2001, 26, 573.

10. E. Tanaka, J. Chromatogr. B, 1997, 688, 155.

11. G. F. Van Rooyen, D. Badenhorst. K. J. Swart, H. K. L. Hundt, T. Scanes, and A. F. Hundt, J. Chromatogr. B, 2002, 769, 1 .

12. S. Hartter, J. Birte, H. Christoph, L. Marytza, W. Haraid, and U. Claus, J. Chromatogr. B, 1998, 712, 253.

13. G. Izzo, M. A. Raggi, B. Maichel, and E. Kenndler, $J$. Chromatogr. B, 2001, 752, 47.

14. M. Contin, R. Riva, F. Albani, E. Perucca, and A. Baruzzi, Ther. Drug Monit., 1985, 7, 46.

15. W. K. Nonidez and D. E. Leyden, Anal. Chim. Acta, 1978, 96, 401.

16. M. A. Targove and N. D. Danielson, J. Chromatogr. Sci., 1990, 28, 505.

17. G. M. Greenway, A. W. Knight, and P. J. Knight, Analyst, 1995, 120, 2549

18. N. Egashira, H. Kumasako, Y. Kurauchi, and K. Ohga, Anal. Sci., 1992, 8, 713.

19. E. A. Seddon and K. R. Seddon, "The Chemistry of Ruthenium", 1984, Elsevier Science Publishers B. V., Amsterdam.

20. H. Y. Han, Z. K. He, and Y. E. Zeng, Anal. Chim. Acta, 1999, 402, 113.

21. F. A. Aly, S. A. Al-Tamimi, and A. A. Alwathan, Anal. Chim. Acta, 2000, 416, 87.

22. Z. He, H. Gao, L. Yuan, S. Lu, H. Meng, X. Li, and Y. Zeng, Talanta, 1998, 47, 301.

23. S. H. Lee, J. J. Nam, and B. M. Son, Bull. Korean Chem. Soc., 2003, 24, 246.

24. R. D. Gerrdi, N. W. Barnett, and P. Jones, Anal. Chim. Acta, 1999, 388, 1.

25. J. N. Demas and A. W. Adamson, J. Am. Chem. Soc., 1973, 95, 5159.

26. W. Y. Lee and T. A. Nieman, Anal. Chim. Acta, 1996, 334 18. 